\title{
Alterations in the Smad4 gene in hamster pancreatic duct adenocarcinomas and established cell lines
}

\author{
KYOKO SHIMIZU ${ }^{1}$, TSUKASA KITAHASHI ${ }^{2}$, HIROMASA FUJII ${ }^{3}$, MASAHIRO TSUTSUMI ${ }^{5}$, \\ TOSHIO MORI $^{4}$, KANYA HONOKI ${ }^{3}$ and TOSHIFUMI TSUJIUCHI ${ }^{1}$
}

\begin{abstract}
${ }^{1}$ Laboratory of Cancer Biology and Bioinformatics, Department of Life Science, Faculty of Science and Technology, Kinki University, Osaka; ${ }^{2}$ Department of Food Science and Nutritional Health, Kyoto Prefectural University, Kyoto; ${ }^{3}$ Department of Orthopedic Surgery and ${ }^{4}$ RI Center, Nara Medical University; ${ }^{5}$ Pathology, Saiseikai-Chuwa Hospital, Nara, Japan
\end{abstract}

Received December 28, 2005; Accepted February 22, 2006

\begin{abstract}
Alterations of the Smad4 gene, identified as a mediator of the transforming growth factor- $\beta$ pathway, were investigated in hamster pancreatic duct adenocarcinomas (PDAs) and established cell lines. Female Syrian golden hamsters received $70 \mathrm{mg} / \mathrm{kg}$ of $\mathrm{N}$-nitrosobis(2-oxopropyl)amine (BOP) followed by repeated exposure to an augmentation pressure regimen consisting of a choline-deficient diet combined with DL-ethionine then L-methionine and a further administration of $20 \mathrm{mg} / \mathrm{kg}$ BOP. A total of 12 PDAs obtained 10 weeks after beginning the experiment and three cell lines established from subcutaneously transplantable PDAs in syngeneic hamsters were examined for mutations using reverse transcription-polymerase chain reaction-single strand conformation polymorphism (RT-PCR-SSCP) analysis. A mutation was detected in only one PDA $(1 / 12,8.3 \%)$ in the form of an ACC to ATC (Thr to IIe) transition at codon 73; none were detected in the three cell lines. No reduced or increased expression of the Smad4 gene was detected in any case using real-time quantitative RT-PCR. These results suggest that the Smad4 gene might play a role in limited fraction of BOP-induced pancreatic duct carcinogenesis in hamsters.
\end{abstract}

\section{Introduction}

Smad proteins are central mediators of the transforming growth factor $\beta$ (TGFß) signaling pathway (1-3). After activation by ligand binding, TGF 3 receptors stimulate the phosphorylation of Smad proteins, which form heterometric complexes with Smad4. These complexes accumulate in the nucleus, where they control gene expression in a cell-type

Correspondence to: Dr T. Tsujiuchi, Laboratory of Cancer Biology and Bioinformatics, Department of Life Science, Kinki University, 3-4-1 Kowakae, Higashiosaka, Osaka 577-8502, Japan E-mail: ttujiuch@life.kindai.ac.jp

Key words: Smad4, pancreatic duct adenocarcinoma, hamster, nitrosamine specific and ligand dose-dependent manner with transcriptional factors, coactivators and corepressors (4-6). Smad4 has been mapped to chromosome $18 \mathrm{q}$ (7), and a high frequency of Smad4 genetic alterations have been observed in human pancreatic carcinomas (7), suggesting that the Smad4 gene is the target tumor suppressor gene of $18 \mathrm{q}$ loss of heterozygosity (LOH) (7).

Pancreatic duct adenocarcinomas (PDAs) have one of the lowest cure rates among human malignancies $(8,9)$; therefore, it is of great importance that we understand the molecular mechanisms underlying pancreatic ductal carcinogenesis. However, at present, information on rate-limiting molecular events is exceedingly limited. Experimental models suitable for the investigation of human PDA development have been established in hamsters using the carcinogen, $N$-nitrosobis(2oxopropyl)amine (BOP), and related compounds (10-12), and we previously developed a rapid production approach to facilitate studies on the underlying mechanisms (13-15). We have reported several genetic changes in this model. For example, a high frequency of Ki-ras mutations were found at early stages, along with p53 mutations, during pancreatic ductal carcinogenesis (16-18). In addition, we provided evidence that overexpression of the midkine and aberrant transcript of Fhit might also be involved in the development of PDAs $(19,20)$. In the present study, to assess involvement of the Smad4 gene in hamster pancreatic duct carcinogenesis, we investigated alterations of the Smad4 gene in hamster PDAs induced by BOP and three established cell lines.

\section{Materials and methods}

Animals and treatment. A total of 18 female Syrian golden hamsters, weighing approximately $100 \mathrm{~g}$ each, were used (Japan SLC Inc., Shizuoka, Japan). PDAs were induced in 12 animals according to the rapid production model (13-15). Briefly, BOP (30 mg/kg body weight) (Nakalai Tesque, Inc., Kyoto, Japan) was given subcutaneously at initiation, followed by two cycles of augmentation pressure, which consisted of choline-deficient diet administration and ethionine-methionineBOP injection. To obtain normal control tissue, including the pancreas, the remaining 6 animals were untreated and maintained free from carcinogen exposure throughout the 
experimental period. All hamsters were sacrificed under light ether anesthesia 10 weeks after beginning the experiment, and the pancreas was immediately excised. Macroscopically apparent tumors were dissected from the surrounding tissue and frozen in liquid nitrogen. Portions of the tumors were also fixed in $10 \%$ neutrally buffered formalin at $4^{\circ} \mathrm{C}$, routinely processed for paraffin embedding, sectioned and stained with hematoxylin and eosin for histological examination.

Cell lines. Details of the establishment of the three cell lines, HPD-1NR, HPD-2NR and HPD-3NR, were reported previously (21). Frozen cell lines were cultured in Dulbecco's modified Eagle's medium (Nissui Pharmaceutical Co. Ltd., Tokyo, Japan) containing 10\% fetal bovine serum (Flow Laboratories, McLean, VA), 2 mM L-glutamine, $100 \mathrm{U} / \mathrm{ml}$ penicillin, and $100 \mathrm{mg} / \mathrm{ml}$ streptomycin sulfate.

RNA extraction and detection of hamster Smad4 gene cDNA. Total RNA was prepared from frozen normal liver tissue using an Isogen kit (Nippon Gene, Inc. Toyama, Japan), and firststrand cDNA was synthesized from $1 \mu \mathrm{g}$ aliquots using Readyto-Go Your-Prime first-strand beads (Amersham Pharmacia Biotech Co. Ltd., Tokyo, Japan). To determine the sequence of the open reading frame (ORF) and 5' upstream and $3^{\prime}$ downstream regions, PCR amplifications were performed with primer sets based on the rat Smad4 cDNA sequence (GenBank accession no. AF170064) as described previously (22). The amplified products were separated on $2 \%$ NuSieve agarose gels (BMA, Rockland, ME) containing $0.05 \mu \mathrm{g} / \mathrm{ml}$ ethidium bromide and then extracted and directly sequenced using a BigDye Terminator v3.0 cycle sequencing ready reaction kit (Applied Biosystems Japan Ltd., Tokyo, Japan) and an ABI PRISM 310 genetic analyzer (Applied Biosystems Japan Ltd.).

Reverse transcription-polymerase chain reaction single-strand conformation polymorphism (RT-PCR-SSCP) analysis. Total RNA was prepared from the 12 frozen PDA samples, 3 cell lines and 3 normal pancreas specimens using an Isogen kit (Nippon Gene, Inc.), then first-strand cDNA was synthesized from $0.2 \mu \mathrm{g}$ aliquots with Ready-to-Go Your-Prime FirstStrand beads (Amersham Pharmacia Biotech Co. Ltd.). To eliminate possible false positives caused by residual genomic DNA, all samples were treated with DNase.

RT-PCR-SSCP analysis was performed using the primers listed in Table I. All were designated from the hamster Smad4 cDNA sequence obtained in the above analysis. The MH-1 domain was amplified with $1 \mathrm{~F}-1 \mathrm{R}$ and $2 \mathrm{~F}-2 \mathrm{R}$ primer sets, and the $\mathrm{MH}-2$ domain with $3 \mathrm{~F}-3 \mathrm{R}, 4 \mathrm{~F}-4 \mathrm{R}$, and $5 \mathrm{~F}-5 \mathrm{R}$ primer sets. Briefly, PCR for SSCP was performed in $10 \mu \mathrm{l}$ of reaction mixture containing $1 \mu \mathrm{M}$ of each primer, $200 \mu \mathrm{M}$ of each dNTP, 1X PCR buffer (Perking-Elmer, Applied Biosystems Division, Foster City, CA), 2.5 units of Ampli Taq (PerkingElmer) and $0.5 \mu 1$ of synthesized cDNA mixture under the following reaction conditions; primary denaturation for $2 \mathrm{~min}$ at $95^{\circ} \mathrm{C}, 30$ cycles of 30 -sec denaturation at $95^{\circ} \mathrm{C}, 30$-sec annealing at $56-64^{\circ} \mathrm{C}, 1-\mathrm{min}$ extension at $72^{\circ} \mathrm{C}$, and a final extension for $10 \mathrm{~min}$ at $72^{\circ} \mathrm{C}$. PCR products were diluted with $10 \mu 1$ of loading solution containing $90 \%$ formide, $20 \mathrm{mM}$ EDTA and $0.05 \%$ xylene cyanol and bromophenol blue.
Table I. Primers used for the RT-PCR-SSCP and real-time RT-PCR analyses.

\begin{tabular}{llc}
\hline & Primers & $\begin{array}{c}\text { Annealing } \\
\text { temp }\left({ }^{\circ} \mathrm{C}\right)\end{array}$ \\
\hline 1F & 5'-GCCTGTCTGAGCATTGTACAT-3' & 62 \\
1R & 5'-CCTCCATAGACGGGCATAG-3' & \\
2F & 5'-TCAGGTGGCTGGTCGGAAAG-3' & 58 \\
2R & 5'-TACTTGGTGGAGCATTACTCT-3' & \\
3F & 5'-TCCTGCTCCTGAGTATTGG-3' & 56 \\
3R & 5'-AGTAACTCTGCACAAAGACTG-3' & \\
4F & 5'-GTTTGGGTCAGGTGCCTTAG-3' & 63 \\
4R & 5'-CAGCAGCAGACAGACTGATTG-3' & \\
5F & 5'-CTGGGTCCGTAGGTGGAATAG-3' & 64 \\
5R & 5'-GCATGGTGTGAAGCACTTCAT-3' & \\
FR & 5'-CTGGCGACGCTGTTCATAAGA-3' & 64 \\
RR & 5'-GCTGCATCTGCCGGTGAC-3' & \\
\hline
\end{tabular}

Aliquots containing $6 \mu 1$ of diluted products were electrophoresed on polyacrylamide gel using a GeneGel Excel 12.5/24 kit (Amersham Pharmacia Biotech Co. Ltd.) at $5^{\circ} \mathrm{C}$, $10^{\circ} \mathrm{C}, 15^{\circ} \mathrm{C}$ and $20^{\circ} \mathrm{C}$ for $90 \mathrm{~min}$ at $15 \mathrm{~W}$ with a GenePhor electrophoresis unit (Amersham Pharmacia Biotech Co. Ltd.). After electrophoresis, the gels were stained using a DNA silver-staining kit (Amersham Pharmacia Biotech Co. Ltd.).

DNA nucleotide sequencing. Following RT-PCR-SSCP analysis, DNA fragment from the abnormal shift band in the gel was extracted and reamplified. The obtained PCR product was directly sequenced using a BigDye Terminator v3.0 Cycle Sequencing Ready Reaction kit (Applied Biosystems Japan Ltd.) and ABI PRISM 310 genetic analyzer (Applied Biosystems Japan Ltd.). To confirm the results, PCR amplification was repeated using the same samples and each PCR product was sequenced with the forward and reverse primers at least twice.

Preparation of a cDNA probe and Southern blot analysis. A $1.775-\mathrm{kb}$ cDNA fragment of the hamster Smad4 gene was obtained by RT-PCR using primer 5'-AGAAACTGGAGA GTTTGATT-3' and 5'-CTTCAGATTATAAACAGGGT-3'. The amplified product was subcloned and confirmed by sequencing and used as the hybridization probe for Smad4.

Genomic DNAs were extracted from frozen tissue of 6 PDAs, 3 cell lines and 3 normal pancreas samples using a DNeasy tissue kit (Qiagen, Hilden, Germany). After digestion with the restriction enzyme HindIII (Takara, Kyoto, Japan), which does not cut the ORF of hamster Smad4 cDNA, 7- $\mu \mathrm{g}$ DNA samples were fractioned by size in $1 \%$ agarose gel, blotted onto Hybond-XL membranes (Amersham Pharmacia Biotech, Buckinghamshire, UK), and hybridized with a $\left[\alpha^{-32} \mathrm{P}\right] \mathrm{dCTP}$ radiolabeled Smad4 probe using a Rediprime II random prime labeling system (Amersham Pharmacia Biotech). Blots were washed and then placed in contact with Hyperfilm MP (Amersham Pharmacia Biotech) at $-80^{\circ} \mathrm{C}$. 
(A)

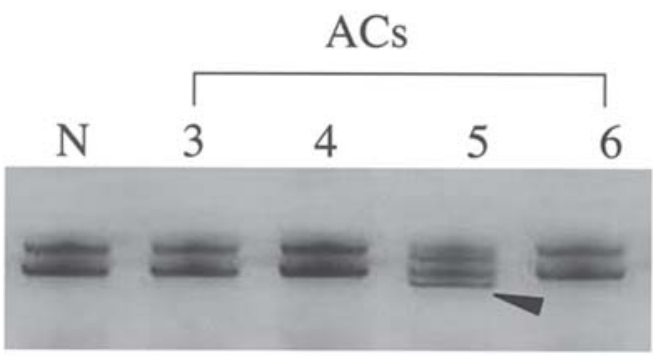

(B)
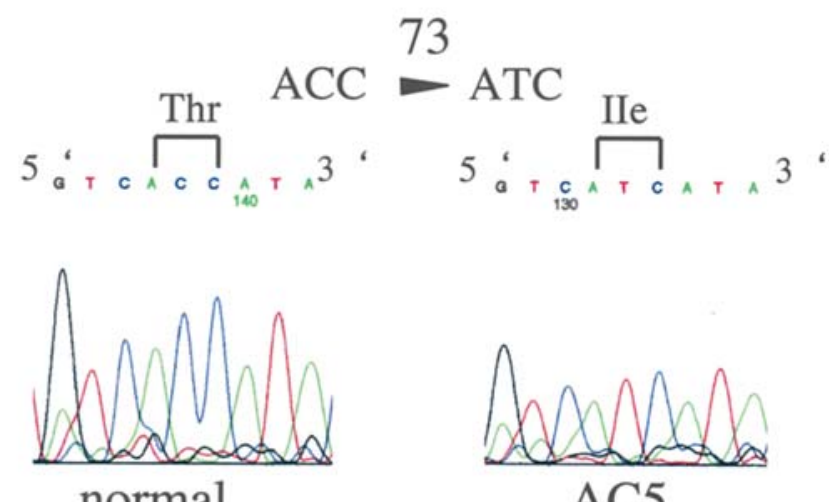

normal

Figure 1. Point mutation of the Smad4 gene. (A) Representative results of RT-PCR-SSCP analysis. The arrowhead indicates an abnormal band shift. $\mathrm{N}$, normal pancreas; ACs, adenocarcinomas. (B) The mutation patterns of the Smad4 gene detected by sequencing analysis. Normal, normal pancreas; $\mathrm{AC}$, adenocarcinoma.

Real-time quantitative RT-PCR analysis. To assess expression of the Smad4 gene, real-time quantitative RT-PCR analysis using a Smart Cycler II System (Takara Bio, Inc., Shiga, Japan) and SYBR Premix Ex Taq (Takara) was performed according to the manufacturer's protocol. Six normal pancreas tissues were used as controls in this analysis. One $\mu 1$ of the cDNA synthesized from each sample was used in the following assay. The primers for Smad4 were newly designed as FR and RR (Table I). The rat glyceraldehyde-3-phosphate dehydrogenase (Gapdh) gene was used as an internal control (23). To obtain the standard curve for each gene, cDNA synthesized from hamster normal liver tissue was used. The amplification plots of the PCR reaction were used to determine the threshold cycle $(\mathrm{Ct})$, which represents the first cycle in which there was a significant increase in fluorescence above the background fluorescence. The initial copy number of the target mRNA was calculated using a plot of the Ct against the input target quantity. Target gene data were normalized to that of Gapdh. Each assay was repeated at least twice for confirmation. Data were statistically analyzed using the Student's t-test.

\section{Results}

PDAs developed in all 12 hamsters treated with BOP, and one from every hamster was obtained for RT-PCR-SSCP and RT-PCR analyses. All PDAs used in this study were histologically well-differentiated. Of these, 6 were $>7 \mathrm{~mm}$ in

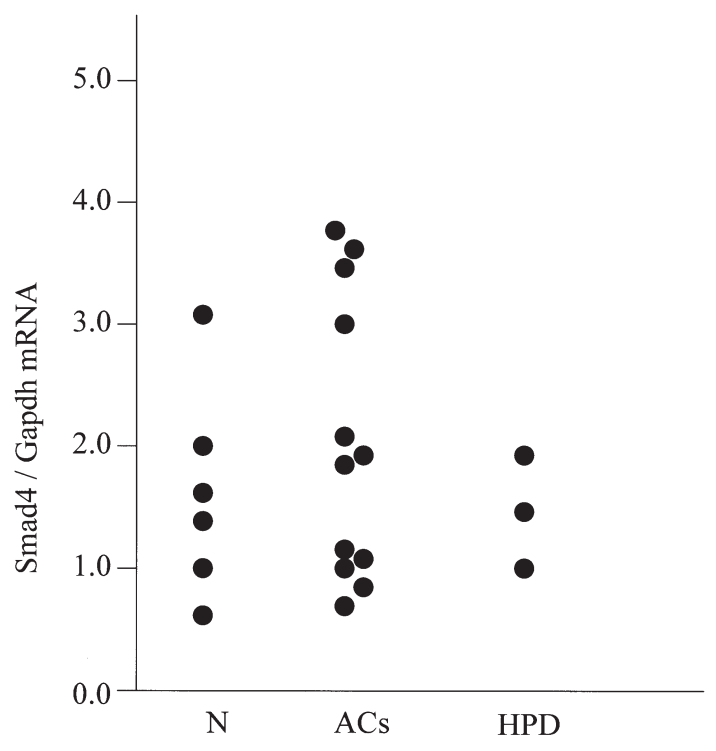

Figure 2. Expression levels of Smad4 mRNA relative to Gapdh mRNA. N, normal pancreas; ACs, adenocarcinomas; HPD, hamster PDA cell line.

diameter and could be used in additional Southern blot analysis. Since PDAs include normal fibroblasts, three cell lines were also used for RT-PCR-SSCP, RT-PCR and Southern blot analyses. We detected the ORF of the hamster Smad4 gene cDNA sequence (GenBank accession no. AB209970) and were thus able to designate primers for the RT-PCR-SSCP analysis.

Using primers to amplify the MH1 and MH2 domains (Table I), the PCR products showed a clear single band in $1 \%$ agarose gels (data not shown). Representative results of the RT-PCR-SSCP and sequencing analysis are shown in Fig. 1A and B, respectively. One of 12 PDAs (8.3\% incidence) indicated an abnormal band shift in the MH1 domain using a primer set of $1 \mathrm{~F}$ and $1 \mathrm{R}$. Sequence analysis revealed the mutation to be an ACC to ATC (Thr to IIe) transition at codon 73 . This sample was one of the smaller tumors $(<7 \mathrm{~mm})$. No mutations were found in the $\mathrm{MH} 2$ domain, and no homozygous deletions were apparent in the $\mathrm{MH} 1$ and $\mathrm{MH} 2$ domains. No mutations or homozygous deletions were detected in the three cell lines. Normal sized PCR products amplified from the MH1 and MH2 domains indicated no mutations (data not shown). Southern blot analysis using a probe including the MH1 and MH2 domains showed no abnormal restriction patterns such as gross genomic rearrangement or homozygous deletion in the 6 PDAs and 3 cell lines (data not shown).

The results of semi-quantitative RT-PCR analysis are shown in Fig. 2. No reduced or increased expression of the Smad4 gene was detected in the 12 PDAs or 3 cell lines compared with 6 normal pancreas samples. There were no statistically significant differences.

\section{Discussion}

The present investigation demonstrated infrequent mutations, no genomic rearrangement or homozygous deletion and no reduced expression in the Smad4 gene in BOP-induced hamster PDAs and three established cell lines. These results 
suggest that alterations in the Smad4 gene might play a role in a limited fraction of nitrosamine-induced hamster pancreatic duct carcinogenesis.

In human PDAs, a high frequency of Smad4 gene mutations has been reported (20\%) (7). Mutations of the Smad4 gene have been also found in human colorectal carcinomas $(<10 \%)$, biliary tract carcinomas $(16 \%)$ and lung cancer $(10 \%)$ (7,24-28), albeit at a rather low frequency. Thus, it has been suggested that inactivation of the Smad4 gene might play a role in pancreatic cancer and possibly other human cancers. In the case of rodents, we previously reported a low frequency of Smad4 mutations in rat lung adenocarcinomas induced by $\mathrm{N}$-nitrosobis(2-hydroxypropyl)amine (8.3\%) (22) and no mutations in rat hepatocellular carcinomas induced by $N$ nitrosodiethylamine (29). The present study showed only one mutation in 12 hamster PDAs and three established cell lines. It is unclear why the frequency of Smad4 mutation is so different in the PDAs of humans and hamsters. It seems that other factors, such as chronic oxidative stress, may be more involved than nitrosocompounds in the induction of Smad4 mutations. In fact, it is well-established that 8-hydroxyguanine, a representative feature of oxidative DNA damage, induces $G$ to $\mathrm{T}$ or A to $\mathrm{C}$ transversions in E. coli (30).

Smad proteins consist of two conserved domains, the $N$-terminal MH1 domain and C-terminal MH2 domain. The $\mathrm{MH} 2$ domain is responsible for inactivation and homo- and hetero-oligomerization, whereas the MH1 domain exhibits sequence-specific DNA binding activity and negatively regulates $\mathrm{MH} 2$ domain function $(6,31,32)$. The central region simply serves as a linker. Therefore, in the present study, we focused on mutations in the MH1 and MH2 domains of Smad4. In fact, the majority of Smad4 mutations in human cancers are located in the MH2 domain (6,7,24-27). In human PDAs, mutations of the Smad4 gene were shown to be mainly located in the MH2 domain (7). However, one mutation found in this study was located in the MH1 domain and not the MH2 domain.

It is well known that nitrosamines are widely distributed in the environment $(33,34)$. G/C to $\mathrm{A} / \mathrm{T}$ transition is considered a common mutation induced by methylating $\mathrm{N}$-nitorosocompounds (35). Our previous report showed a $\mathrm{G} / \mathrm{C}$ to $\mathrm{A} / \mathrm{T}$ transition of the Ki-ras gene in hamster PDAs induced by BOP (57\%), suggesting that Ki-ras mutations might be caused by the nitrosocompound $(16,17,36)$. In the present study, the detected smad4 mutation indicated a $\mathrm{C} / \mathrm{G}$ to $\mathrm{T} / \mathrm{A}$ transition and might also be the result of nitrosocompound. However, this mutation was found in only one PDA, while Ki-ras mutations were detected in PDAs and preneoplastic lesions, such as hyperplasias and adenomas $(16,17)$. Therefore, it seems that the Smad4 gene might not be the main target of nitrosocompounds in hamster pancreatic duct carcinogenesis. Although homozygous deletions were previously found in $30 \%$ of human PDAs (7), we found no DNA rearrangement or homozygous deletions in hamster PDAs (data not shown). It has also been reported that human lung cancers frequently show tumor-specific aberrant hypermethylation at $18 \mathrm{q} 21$, demonstrating that smad4 itself might be inactivated by transcriptional repression due to aberrant hypermethylation (37). The present study indicated no reduced expression of the Smad4 gene in hamster PDAs and three established cell lines, suggesting no involvement of aberrant hypermethylation. The involvement of LOH remains to be clarified.

In conclusion, taken together with our previous findings $(22,28)$, the results of this study show that alterations in the Smad4 gene might play a limited role during nitrosaminerelated carcinogenesis in rodents. We previously reported alterations in TGFß signaling pathway-associated genes, such as TGFß receptor II, Smad2 and mannose 6-phospate/insulinelike growth factor II receptor genes, in rat lung adenocarcinomas induced by $N$-nitrosobis(2-hydroxypropyl)amine $(22,38,39)$, with tumor cells expressing higher levels of TGFß than normal lung tissue (40). To understand the involvement of the TGFß signaling pathway in BOP-induced hamster pancreatic ductal carcinogenesis, further studies of alterations in these genes in hamster PDAs are required.

\section{Acknowledgements}

This study was supported in part by a Grant-in-Aid for Cancer Research from the Ministry of Health, Labor and Welfare of Japan, the Foundation for Promotion of Cancer Research in Japan, and a Grant-in-Aid (RK17-027) from the Faculty of Science and Engineering, Kinki University.

\section{References}

1. Derynck R, Gelbart W, Harland R, et al: Nomenclature: vertebrate mediators of TGFß family signaling. Cell 87: 173, 1996.

2. Derynck R and Zhang Y: Intracellular signaling: The Mad way to do it. Curr Biol 6: 1226-1229, 1996.

3. Massague J: TGF- $\beta$ signaling: Receptors, transducers, and Mad protein. Cell 85: 947-950, 1996.

4. Liu F, Hata A, Baker JC, et al: A human Mad protein acting as a BMP-regulated transcriptional activator. Nature 381: 620-623, 1996.

5. Yingling JM, Das P, Savage S, et al: Mammalian dwarfins are phosphorylated in response to transforming growth factor $B$ and are implicated in control of cell growth. Proc Natl Acad Sci USA 93: 8940-8944, 1996.

6. Ten Dijke P and Hill CS: New insights into TGF-ß-Smad signaling. Trends Biochem Sci 29: 265-273, 2004.

7. Hahn SA, Schutte M, Hoque AT, et al: Dpc4, a candidate tumor suppressor gene at human chromosome 18q21.1. Science 271: 350-353, 1996.

8. Wingo PA, Ries LA, Giovino GA, et al: Annual reports to the nation on the status of cancer, 1973-1996. J Natl Cancer Res 92: 675-690, 1999.

9. Yamamoto M, Ohashi O and Saitoh Y: Japan pancreatic cancer registry: Current status. Pancreas 16: 238-242, 1998.

10. Pour P, Kruger FW, Althoff J, et al: Cancer of the pancreas induced in the Syrian golden hamsters. Am J Pathol 76: 349-358, 1974.

11. Pour PM, Salmasi SZ and Runge RG: Selective induction of pancreatic ductal tumors by single dose of $N$-nitrosobis(2oxopropyl)amine in Syrian golden hamsters. Cancer Lett 4: 317-323, 1978.

12. Pour PM, Runge D, Birt D, et al: Current knowledge of pancreatic carcinogenesis in the hamster and its relevance to the human disease. Cancer 47: 1573-1589, 1981.

13. Mizumoto K, Tsutsumi M, Denda A, et al: Rapid production of pancreatic carcinoma by initiation with $N$-nitrosobis(2-oxopropyl) amine and repeated augmentation pressure in hamsters. J Natl Cancer Inst 80: 1564-1567, 1988.

14. Mizumoto K, Tsutsumi M, Ito S, et al: Cycle of repeated augmentation pressure in rapid production of pancreatic and cholangiocellular carcinomas in hamsters initiated with $N$ nitrosobis(2-oxopropyl)amine. Carcinogenesis 10: 1457-1459, 1989.

15. Mizumoto K, Tsutsumi M, Kitazawa S, et al: Usefulness of rapid production model for pancreatic carcinoma in male hamsters. Cancer Lett 49: 211-215, 1990. 
16. Tsutsumi M, Murakami Y, Kondoh S, et al: Comparison of $\mathrm{K}$-ras oncogene activation in pancreatic duct carcinomas and cholangiocarcinomas induced in hamsters by $N$-nitrosobis(2oxopropyl)amine. Jpn J Cancer Res 84: 956-960, 1993.

17. Tsutsumi M, Kondoh S, Noguchi O, et al: K-ras gene mutation in early ductal lesions induced in a rapid production model for pancreatic carcinomas in Syrian hamsters. Jpn J Cancer Res 84: 1101-1105, 1993

18. Okita S, Tsutsumi M, Onji Y, et al: p53 mutation without allelic loss and absence of mdm-2 amplification in a transplantable hamster pancreatic ductal adenocarcinomas in hamsters. Mol Carcinog 13: 266-271, 1995.

19. Tsutsumi M, Kadomatsu K, Tsujiuchi T, et al: Overexpression of midkine in pancreatic duct adenocarcinomas induced by $\mathrm{N}$ nitrosobis(2-oxopropyl)amine in hamsters and their cell lines. Jpn J Cancer Res 91: 979-986, 2000.

20. Tsujiuchi T, Sasaki Y, Kubozoe T, et al: Alterations in the Fhit gene in pancreatic duct adenocarcinomas induced by $N$ nitrosobis (2-oxopropyl)amine in hamsters. Mol Carcinog 36: 60-66, 2003.

21. Mori T, Tsutsumi M, Noguchi O, et al: Characterization of three cloned cell lines from $N$-nitrosobis(2-hydroxopropyl)amine induced transplantable hamster pancreatic ductal adenocarcinoma. Int J Pancreatol 16: 171-177, 1994.

22. Tsujiuchi T, Sasaki Y, Tsutsumi M, et al: Mutations of the Smad 2 and Smad4 genes in lung adenocarcinomas induced by $N$-nitrosobis(2- hydroxopropyl)amine in rat. Mol Carcinog 29: 87-91, 2000.

23. Abe M, Okochi E, Kuramoto T, et al: Cloning of the 5' upstream region of the rat p16 gene and its role in silencing. Jpn J Cancer Res 93: 1100-1106, 2002.

24. Thiagalingam S, Lengauer C, Leach FS, et al: Evaluation of chromosome 18q in colorectal cancers. Nat Genet 86: 543-552, 1996.

25. Miyaki M, Iijima T, Konishi M, et al: Higher frequency of Smad4 gene mutation in human colorectal cancer with distant metastasis. Oncogene 18: 3098-3103, 1999.

26. Hahn SA, Bartsch D, Schroers A, et al: Mutations of the DPC4/ Smad4 gene in biliary tract carcinoma. Cancer Res 58: 1124-1126, 1998.

27. Nagatake M, Takagi $\mathrm{Y}$, Osada $\mathrm{H}$, et al: Somatic in vivo alterations of the DPC4 gene at 18q21 in human lung cancers. Cancer Res 56: 2718-2720, 1996.
28. Uchida $\mathrm{K}$, Nagateke $\mathrm{M}$, Osada $\mathrm{H}$, et al: Somatic in vivo alterations of the JV18-1 gene at 18q21 in human lung cancers. Cancer Res 56: 5583-5585, 1996.

29. Sasaki Y, Tsujiuchi T, Murata N, et al: Alterations of the transforming growth factor- $\beta$ signaling pathway in hepatocellular carcinomas induced endogenously and exogenously in rats. Jpn J Cancer Res 92: 16-22, 2001.

30. Moriya M, Ou C, Bodepudi V, et al: Site-specific mutagenesis using a gapped duplex vector: a study of translation synthesis past 8-oxodeoxyguanosine in E. coli. Mutat Res 254: 281-288, 1991.

31. Heldin CH, Miyazomo K and ten Dijke P: TGFß signaling from cell membrane to nucleus through SMAD proteins. Nature 390: 465-471, 1997.

32. Kretzschmar M and Masssague J: SMADS: mediators and regulators of TGFß signaling. Curr Opin Genet Dev 8: 103-111, 1998.

33. Mirvish SS: Formation of $N$-nitroso compounds: Chemistry, kinetics and in vivo occurrence. Toxicol Appl Pharmacol 31: 325-351, 1975.

34. Bartsch H and Montesano R: Relevance of nitrosamines to human cancer. Carcinogenesis 5: 1381-1393, 1984.

35. Jiao J, Pienkowska M, Glickman BW, et al: Molecular analysis of mutations induced by ethylating $N$-nitroso compounds in the lac I gene of Eschericha coli. Mutat Res 352: 39-45, 1996.

36. Kitada H, Tsutsumi M, Tsujiuchi T, et al: Frequent mutations of Ki-ras but no mutations of Ha-ras and p53 in lung lesions induced by $N$-nitrosobis(2-hydroxopropyl)amine in rats. Mol Carcinog 15: 276-283, 1996.

37. Nagatake M, Osada H, Kondoh M, et al: Aberrant hypermethylation at the bcl-2 locus at 18q21 in human lung cancers. Cancer Res 56: 1886-1891, 1996.

38. Tsujiuchi T, Sasaki Y, Tsutsumi M, et al: Mutations and reduced expression of the transforming growth factor- $\beta$ receptor II gene in rat lung adenocarcinomas induced by $N$-nitrosobis(2-hydroxopropyl)amine. Jpn J Cancer Res 91: 1090-1095, 2000.

39. Tsujiuchi T, Sasaki Y, Tsuysumi M, et al: Alterations of the M6p/lgf2 receptor gene in lung adenocarcinomas induced by $N$ nitrosobis(2-hydroxopropyl)-amine in rats. Mol Carcinog 36: 32-37, 2003

40. Tsujiuchi T, Sasaki Y, Murata N, et al: Elevated expression of transforming growth factors and the tumor necrosis factor family in lung adenocarcinomas induced by $N$-nitrosobis(2-hydroxopropyl)amine in rats. Exp Toxicol Pathol 53: 291-295, 2001. 